\title{
Reseña
}

\section{Martínez, Rigoberto. 2016. Dominación y resistencia II. Elementos para una teoría de la autoridad simbólica. Chihuahua: CELAPEC.}

Fecha de recepción: 11 de enero del 2018

Víctor Hernández Márquez ${ }^{1}$

Fecha de aceptación: 11 de enero del 2018

$\mathrm{E}$ 1 presente libro se ocupa de uno de los problemas capitales de la filosofía política y de las ciencias sociales que hacen eco de esa tradición de pensamiento. El libro se divide en tres capítulos (1 La sujetación, 2 La autoridad simbólica y 3 La ideología); consta además de un preámbulo y un epílogo. En cierta forma, el libro es una prolongación o extensión del libro anterior del autor La epistemología rupturista. Reflexiones sobre un psicoanálisis del objeto,(IPC-Plaza y Valdes, 2011) en el cual se ocupa de algunos de los problemas de la teoría del conocimiento desde la tradición estructuralista francesa, Freud y ciertas ideas de algunos proponentes de la ola postmarxista. Esto sugiere que para el autor la mejor medicina para combatir dicho mal es una suerte de purga epistemológica.

Pero ¿en qué consiste este problema capital de la filosofía política? Para explesarlo en términos de Etienne de la Boétie y Rousseau, se trata de la cuestión sobre cómo determinar el orígen y el fundamento de la servidumbre voluntaria. O como lo plantea el autor desde el principio: “Por qué los oprimidos contribuimos a mantener una relación de dominación sin necesidad de la presencia del opresor?, ¿Por qué los oprimidos nos convertimos en vigilantes de nuestra propia condición opresiva?".

Rigoberto Martínez piensa que en buena medida la respuesta se halla en la noción de autoridad simbólica y por tal motivo se ocupa en presentar algunos elementos conceptuales para una futura teoría de dicha noción. Los elementos en cuestión consisten en una amalgama de "teoría althuseriana de la sujetación”, psicoanálisis, teoría de la ideología de Marx y una gran variedad de ideas, opiniones y apotegmas de una igual variedad de autores más o manos de moda dentro de los estudios culturales y el pensamiento de izquierda.

Como en el mencionado libro anterior del autor, la estrategia consiste en una suerte de exposición teorética a partir de una hermenéutica de obras literarias (en el caso anterior, la carta robada de Poe, en este

1- Nacionalidad: Mexicana. Grado: Doctorado. Especialización: Filosofía. Adscripción: Universidad Autónoma de Ciudad Juárez. Correo electrónico: victor.hernandez@uacj.mx. (D) ORCID: https://orcid.org/0000-0001-6644-9116

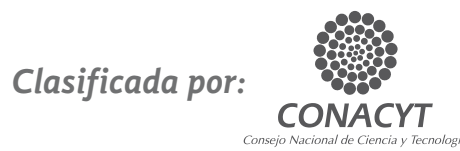


nuevo libro, Edipo Rey de Sófocles), materia psíquica propia del sicoanálisis (sueños y chistes en el libro anterior, y recuerdos en el presente), productos emanados de las industrias culturales (películas como Matrix y Dos días y una noche), así como vivencias del propio autor. Dada la gran tarea que se ha echado a cuestas en tan breve espacio (poco más de un ciento de páginas) y pese a la relativa habilidad expositiva de Rigoberto Martínez, el resultado es, a mi juicio, bastante desigual en cuanto al grado de especificación, delucidación y articulación conceptual de todos elementos involucrados. Pero en general, para parafrasear los Elementos de autocrítica de Althusser, diré que la propuesta de Rigoberto adolece más que de errores particulares, de una desviación teoricista. O para volver una vez más al cuestionamiento escéptico del matemático Giussepe Peano: ¿Pero realmente hace todo esto más barato el pan?

Ahora bien, al parecer Rigoberto piensa que el estudio de la participación activa del oprimido en su propia opresión es un asunto relativamente nuevo, que empieza con Wilhelm Reich, Gramsci, Lukács, etc. guardando silencio sobre la venerable tradición que le precede. La omisión es aún más sorprendente tomando en cuenta que Rigoberto ha tomado como punto de partida la tragedia de Edipo Rey para exponer la teoría de la doble sujetación de Althusser. Desde luego, quizá Rigoberto podría pensar, emulando un tanto a Castoriadis, que el pensamiento político social del pueblo griego se puede apreciar mejor en las obras de los poetas e historiados griegos que en los discursos de sus filósofos. Sin embargo, Rigoberto admite que su tratamiento hermenéutico es anacrónico (presentista) y modernista; por consiguiente, sólo recurre a la tragedia de Edipo en tanto pueda echar luz sobre los problemas presentes que representan las relaciones de poder.

Pero si eso puede ocurrir así, solo puede ser a costa de realizar un acto audaz de abstracción que debería ir precedido de una justificación previa que no se encuentra en el libro. Es decir, para que la tragedia de Edipo Rey pueda pasar como una alegoría del problema en cuestión el lector se tiene que hacer de la vista gorda con respecto al estatus social de los héroes que figuran en la citada tragedia; es decir, independientemente de lo que diga la profecía, afín de cuentas Edipo es hijo de Layo y Yocasta, y por consiguiente, forman la familia que gobierna Tebas; por consiguiente, y desde la perspectiva tradicional del problema de la subordinación política, todos ellos se encuentran del lado de quienes conforman la clase previlegiada, no los de la masa oprimida.

En algún momento Edipo considera la posibilidad de que su madre haya sido una esclava de tercera generación (1062-3), pero esto no pasa de ser más que una suposición, de modo que la distinción entre esclavos y hombres libres (políticamente hablando) se asume como algo natural y claramente delimitado, como la distinción que hay entre los dioses y los hombres en toda tragedia griega. Una consecuencia extraña de la propuesta del libro es que los personajes verdaderamente subordinados de la tragedia de Edipo, como el criado, el pastor de ovejas, y el mensajero, figuran como meras comparsas del drama sin que su carácter anónimo (puesto que los conocemos únicamente por su condición servil), despierte la menor consideración o comentario por parte del autor.

Si Rigoberto Martínez es capaz de pasar por alto todos estos detalles es porque abriga la convicción de que en Edipo rey "se encuentra una teoría del sujeto y sus mediaciones ideológicas". Pero el ejercicio hermenéutico es aquí tan escueto que me cuesta trabajo comprender exactamente el fundamento sobre el que se apoya tal afirmación. Por una parte, sostiene que el proceso de sujetación es doble; es decir, los sujetos (Layo, Yocasta y Edipo) se ven sujetados al designio de Apolo artífice de la tragedia que llevará a que Edipo asesine a Layo, su padre, y contraiga nupcias con Yocasta, su madre; pero también se ven sujetados a la creencia de que pueden ejercer su libertar y desafiar la profecía. Y luego sentencia: "En la medida en que el sujeto interioriza la fantasía ideológica de la "libertad" (la creencia de que solo hace falta un acto individual 
de voluntad para desafiar su condición de oprimido) en esa misma medida asume el papel de oprimido sin necesidad de la presencia del opresor".

El principal reparo a la interpretación de Rigoberto no se funda tanto en el hecho constatado por los filólogos de que la noción de voluntad se encuentra ausente del universo léxico de la grecia arcaica y clásica, ${ }^{2}$ como en el sentido laxo que da al término oprimido y opresor así como el identificar sin más una creencia errónea con una fantasía ideológica. Dicho de otro modo, para acceder a la interpretación de autor es menester tomarse demasiadas licencias léxicas pero no es claro por qué habríamos de asumir ese costo, si es que de antemano no compartimos el marco teórico sobre el cual se funda y su pertinencia para responder a la cuestión que da sentido a este libro.

Por el contrario y mientras tanto van quedando en el camino varias cuestiones abiertas que habría que colmar antes de poder continuar. En primer lugar, ¿por qué necesitamos una teoría del sujeto y de sus mediaciones ideológicas? No será que en todo sea más pertinente echar mano de una teoría del no-ser, del no-sujeto y de sus mediaciones ideológicas, o quizá aún mejor, del no-sujeto que se asume como sujeto, para volver sobre los pasos de Fanon que Matínez menciona pero sin advertir las fisuras que provaca en su marco conceptual.

Pero hay más, la teoría del sujeto que presuntamente se requiere para explicar la autosubordinación se halla a su vez mediada por la teoría freudiana del complejo de Edipo, a la cual asocia el origen de la autoridad simbólica, más un poco de desplazamiento del significante lacaniano. Es decir, cuando reprimimos nuestro deseo incestuoso lo hacemos por "el respeto inconsciente a la autoridad" (a la autoridad de la madre en este caso) y cuando nos subordinamos ante otras formas de autoridad es porque realizamos una proyección o desplazamiento del significante de la primera figura afectiva. De modo que, a juicio del autor, si el lector se subordina incondicionalmente a otra autoridad lo hace porque proyecta esa primigenia figura de autoridad en el cura, el policía, etc.

Ya Ricoeur ha llamado desde hace mucho tiempo la atención sobre el problema epistemológico que enfrenta la teoría freudiana al dejar sin resolver el conflicto entre la energética y la hermenéutica; es decir y en nuestro caso, en ubicar el problema de la represión del deseo edípico en el plano de la representación o en el plano de la fuerza psíquica. Y desde luego, puede plantearse si este conflicto se extiende a la "teoría" del desplazamiento del significante y al de la subordinación autoimpuesta. Es muy probable que así sea, pero como siempre se podrá contraargumentar que no existe tal conflicto, porque el plano energético siempre se encuentra como fuente del plano simbólico, no exploraré dicha posibilidad.

En cambio, tomaré una ruta más corta de carácter escéptico; es decir, ¿cómo sabe Freud, Lacan y el autor que esto es así y no de otro modo?, y ya jugando con el propio asunto ¿cómo sabemos que la "teoría" sobre los mecanismos de control simbólico no son así mismo producto de un mecanismo de control intelectual de un deseo ulterior reprimido? No hay en el texto de Martínez Escárcega esta clase de procupaciones metateóricas y en vano el lector encontrara un intento mínimo por someter a controlar las afirmaciones sobre las cuales se construye su narrativa. Y dado que el autor se haya subordinado a la autoridad simbólica de Feud, Lacan y de todos aquellos que cita con aprobación, es de suponer que se encuentra sujetado al mismo deseo reprimido, y así sucesivamente, de tal suerte que la respuesta a la cuestión fundamental sobre la servidumbre incondicional permanece intocado.

2- Cf. Hermann Fränkel, Poesía y filosofía de la Grecia Arcaica, Madrid: Visor, p. 366, n. 52. Martínez desecha varias teoría por su carácter voluntarista, pero sin ofrecer una argumentación de sus fallos sino simplemente contraponiendo su propia filiación teórica asumiendo que es superior, transfiriéndole al lector asumir sin más su propia convicción. 